\title{
Forum
}

PMLA invites members of the association to submit letters, typed and double-spaced, commenting on articles in previous issues or on matters of general scholarly or critical interest. The editor reserves the right to reject or edit contributions for publication and offers the authors discussed an opportunity to reply to the letters published. The journal discourages footnotes and regrets that it cannot consider any letter of more than 1,000 words.

\section{Virginia Woolf and Psychoanalytic Criticism}

To the Editor:

In "Manic-Depressive Psychosis and Critical Approaches to Virginia Woolf's Life and Work" (103 [1988]: 10-23) Thomas C. Caramagno suggests, but does not provide, a welcome antidote to the dehydration of authors by clinically uninformed (if not naive) psychoanalytic critics. One could not agree more with his implicit charge that literature is yoked to the brand of theory that is at stake for the critic. Such a charge might be made against other theoretical architectonics as well, not just analysis. For analysis, however, Caramagno finds an indisputable (monolithic?) objective "test" of validity: biological psychiatry. While one can sympathize with his questions about analytic criticism, two objections must be made to this sort of appeal, one formal and the other methodological.

Methodologically, it is impossible not to be reductive when trading within the discourse of biological reductionism. The objection is simply this: Caramagno gives no evidence for the clinical picture that he alleges. Quoting any particular biobehaviorist does not provide enough support. It is uncomfortably like a clerical appeal to ecclesiastical authority, not unlike the tactic of analytic critics who invoke the authority of Freud.

Indeed, the "authority" that ought to reside with the author and the text is displaced sideways onto psychobiology - a theory that is at least as much ideology as science.

Furthermore, the literature is made to serve biology, no matter how much one might try to recuperate it as "insight" into the experience of some allegedly objective illness. Likewise, analytic critics have too often made literature serve some allegedly objective neurosis. With an author like Woolf, it would seem that the difference, or disjunction, between biology and the body is much more to the point. Psychobiology does not represent a critical corrective, let alone an advance, because determinism by any other name insists in the discourse of psychobiology no less than in analysis.

Formally, there may be a more insidious risk. Psychiatry is cold comfort for anyone seeking to escape the deplorable reductionism of psychoanalytic criticism (itself a conflict, if not a contradiction, in terms). Where the analytic critic would "convict" Woolf of neurosis, the psychobiologist would not even read the literature. Lan- guage has no role in current theories of biobehavioral psychiatry. Certainly there is "language behavior," but in biological psychiatry language has no function akin to its capacity to respond to the multidimensional reality of the existence of any human subject and to convey that multidimensionality to another through reading.

In addition, it must be noted, there are many psychoanalysts, certainly clinically informed, who pursue a link between a theory of affects and a biological substrate in the neuronal structure of memory. They would speak openly today of a future where there will be a biological test of the analytic cure. Indeed, analysis is becoming more and more a form of biological intervention. This situation curiously reiterates the era of biological discourse out of which Freud himself emerged one hundred years ago (as in the "Project"). The idea that there is a "germ" responsible for the visible manifestation of disorder is certainly not new. It is just that very few, if any, actual germs have been found for the syndromes that Freud was the first to diagnose: hysteria, obsession, and the delerium of a Schreber. Certainly, psychobiology has yet to offer anything other than new "descriptions" of an as yet unnamed "germ."

One would like to think that there might come a time when the psychiatrists and psychoanalysts would come to literary scholars to learn something of the context within which to assess the significance of their findings, rather than the other way around that Caramagno's article evidences.

JAMES GLogowski

State University of New York, Buffalo

\section{To the Editor:}

I should like to respond to several issues that Caramagno's essay "Manic-Depressive Psychosis and Critical Approaches to Virginia Woolf's Life and Work" raised about my book Virginia Woolf and the "Lust of Creation": A Psychoanalytic Exploration.

1. Caramagno writes, "Psychoanalytic critics like Panken who desire to 'demystify the aura surrounding Woolf's emotional oscillations' must learn to tolerate and 
value disorder . . . to understand the manic-depressive's world" (18). I do not dismiss "disorder" and ambiguity; rather, referring to the misunderstandings about Woolf's "madness," I challenge the belief that she was "never completely sane." I do not accept the "official theory" that Woolf's suicide attempt in 1913, one year after her marriage, and her later suicide were engendered by anxieties involved in completing her novels. I link her emotional difficulties to oscillations of self-regard in the context of her conflict-ridden personal relationships (Panken 2).

To some degree Woolf colluded with her husband in linking her "madness" with her "excitement" in creating, though obviously she, the quintessential artist, possessed the "power to nuance her emotions in the work, to make shape of her personal maelstrom" (Panken 3).

2. Caramagno claims that I (and others) assume Woolf "became an artist because she was a neurotic" (Caramagno 10). Throughout, I indicate that there is no causal connection between creativity and neurosis or insanity; though Woolf's writing, like all art, reflects personal conflicts, emotions, and fantasies, it "underscored her striving for self-definition, her thrust towards mastery," her iconoclasm in form (Panken 6-7).

3. According to Caramagno, I theorize that " $[\mathrm{w}] \mathrm{hen}$ fiction failed and Woolf realized the illusion of restitution, she became depressed, attempted suicide as an act of atonement and self-sacrifice" (Caramagno 18). I nowhere connect Woolf's depression or suicide attempts to difficulties in writing. I connect Woolf's suicide to the diminution of closeness in her intimate relationships, to her plummeting self-esteem, and to her retaliative rage. I also state that suicide may represent "passive surrender, escape from suffering; need for sacrifice, atonement or restitution; aggression turned against the self or one's internal objects" (267-68).

4. In addition, Caramagno frequently omits context, so that meaning is lost. He alludes to "Panken layering one neurosis over another" (10). More accurately, I say Woolf evidenced character traits of a "mixed" variety, "depressive, obsessive, masochistic, psychosomatic" (5), that her "agitated depression and suicidal bent suggest early traumatic deprivation, a lifelong affective or cyclothymic disposition," with emphasis on the depressive end. When depressed, highly anxious, or physically ill, she interchangeably alluded to "breakdown," "madness," or being at the "edge of a precipice." Though "these warnings express despondency, they are also provocative, coercive and demand attention" (6).

5. Caramagno indicates that I describe Woolf as "selfdestructive, masochistic," and "deeply guilt-ridden" (10). I state: "though Woolf's symptoms can be considered unconscious manipulation via illness, her self-destructive, masochistic orientation appears to far outweigh in suffering whatever gains are present" (Panken 4). I also suggest that Woolf was "deeply guilt-ridden because of her early closeness with her father" and that she might have uncon- sciously considered herself and her father responsible for precipitating her mother's death (13).

6. Caramagno asks, "Did Woolf perceive her body as repulsive, . . . refuse to eat because of lifelong frigidity and self-hatred created by sexual trauma or loss of her mother ?" (18). I do not make these links but simply state that "Virginia's refusal to eat . . . suggests a more severe manifestation of anorexia in 1913 when her sexuality and femininity were in question." Frequently "assuming delusional proportions, Virginia's preoccupations point to self-hatred, distortions concerning bodyimage . . . , her power struggles with caretakers" (68).

7. Caramagno says that I portray Woolf as "humiliated by her sexual inhibitions and victimized by a 'passive aggression that masks oral rage'," (Caramagno 10). Rather, I believe that Leonard, in not desiring children, "rejected Virginia as a woman, forbidding babies and sex, which eventuated in her profound sense of humiliation and failure regarding her sexual and maternal roles . . . "(70). I also say that Woolf's avoidance of food "may defend against fear of engulfment" and that here "passive aggression masks oral rage" (68).

8. Caramagno asserts, "For Panken even the physical symptoms of Woolf's breakdown evidence . . . need for punishment due to early developmental trauma" (Caramagno 10). Actually I write, "In highly anxietyprovoking circumstances, Woolf's need for punishment via physical symptoms, her inner despair and submerged rage, synchronized with her depression and preoccupation with suicide" (16).

The central thrust of Caramagno's study, based on an article by a psychiatrist, Sherman C. Feinstein, is that literary critics avoid the "biological implications" of Woolf's illness. Caramagno adds that manic-depressive breakdowns are associated with "neurohormonal disbalance, a complex amalgam of alternations in the levels and functions of amino neurotransmitters" (12). He negates psychological, especially "Freudian," interpretations; these, he claims, erroneously consider the manicdepressive disorder a neurosis. Caramagno insists that in this disorder "many shifts of mood or even complete breakdowns cannot be traced to an exterior or 'psychological' cause" (12). He overexalts the simple, biological explanation, though an earlier paper coauthored by Feinstein affirms the importance of intrapsychic conflict (Feinstein and Wolpert, "Juvenile Manic-Depressive Illness," Journal of the American Academy of Child Psychiatry 12 [1973]: 123-36).

Actually, one cannot be certain of precipitating causes, inasmuch as "bipolar" personalities are highly prone to denial of psychic pain. Strictly organic theories of mental illness have been promulgated from Hippocratic to modern times. Feinstein's is not the definitive study of Woolf's malady by a psychiatrist: Kimaya, Fish, and Kubie, psychiatrists who individually wrote on Woolf's illness, reflect the difficulties of psychiatric diagnosis. Nor do Freudians disregard biological aspects of affective dis- 
orders, as Caramagno claims they do, but allude to "constitutional," "endogenous," or "hereditary" concomitants.

Recent investigations summarizing the "biogenic amine hypothesis"-the implications of catecholamines (epinephrine, norephrinephrin, dopamine) and indole amines (serotonin and histamine) in the neurophysiological pathology of the manic-depressive disorder-indicate that early studies pointing to high or low levels of neurotransmitter at critical synapses have not been validated (S. Jackson, Melancholia and Depression, New Haven: Yale UP, 1985). New, accumulating data on the biochemistry of the condition present a confusing, incomplete picture and have not as yet been encompassed within a unitary theoretical framework.

A more meaningful approach to comprehending affective disorders is the psychosomatic, where psyche also affects soma. Concerning the psychological modality, the crucial components are issues concerning Woolf's early narcissistic injury and vulnerability: sense of loss, envy, and damage; fragility of self; and masked rage.

\section{SHIRLEY PANKEN}

New York, New York

\section{To the Editor:}

Thomas C. Caramagno's "Manic-Depressive Psychosis and Critical Approaches to Virginia Woolf's Life and Work" uses an interesting discussion of the physical, as opposed to psychical, causes of Woolf's particular psychosis in a misguided attempt to debunk Freud and psychoanalytic literary criticism. Although I share, to some extent, Caramagno's criticism of psychobiographers who suggest that "Woolf became an artist because she was a neurotic, that she filled her books with references to death and strange desires for a depersonalized union with the cosmos because she was afraid to live fully outside fiction" (10), it seems to me that this article not only misrepresents psychoanalytic critics in general by excluding those who are more interested in analyzing texts than authors but also dangerously dismisses the Freudian method of the "talking cure" in the struggle to alleviate even somatic-induced symptoms. By Caramagno's own admission, psychotic biochemical symptoms, although "not primarily an environmentally induced or learned disorder," nevertheless are "certainly modified by the individual's personality and personal history" (12). Caramagno attempts, by way of a "revelation" of the somatic causes of manic-depressive psychosis, to undermine psychoanalysis both as a method of relieving oppressive symptoms and as a literary method of producing meaning and significance in the text.

The question of the somatic and psychical causes of psychosis seems to be far from settled, despite Caramagno's assertions to the contrary. Nevertheless, his ex- planation of Woolf's relation to her creative process in the light of her somatically induced mental illness seems to belie his implication that this particular form of psychosis may at best be alleviated by medication (12). If this were true, we need not investigate much further the relations between the creative process and mental illness. But after attacking psychoanalytic critics for suggesting that Woolf's art was a means of representing unconscious material, Caramagno offers us his own version of the creative process as therapy, insofar as her writing "represent[s] a perplexing and biographically meaningless disorder in perception and mood" and insofar as Woolf was able to "adapt" to her illness by giving herself "the opportunity to explain her illness, to represent it, without simplification" $(19,22)$.

Caramagno finds reductionism and simplification in what Freudian critics do to a text, the bringing to consciousness of unconscious content. Psychoanalytic critics, according to Caramagno, "reduce" a complicated and ambiguous text to "an order [of meaning] that we fail to remember is fictitious itself" (17). Not only has Caramagno entirely misjudged the nature of psychoanalytic interpretation as Freud has presented it in his study of dreams, he himself seems to have forgotten the "fictitious" nature of meaning when he suggests that "analytical fiction[s]" shield the critic (an instance of the critic's own projections) "against meaning" and interfere with the "ability to interpret correctly" (17). To insist that an interpretation is "fictitious" on the one hand and that it may be "correct" on the other seems, indeed, to be a lapse of memory, if not a contradiction. In his attempt to castigate psychoanalytic critics for their blindness to the problem of countertransference, the act of creating fictitious interpretations, Caramagno appears to suffer from his own form of blindness, to the extent that he offers us his reductive meaning of the text: that Woolf's novels reflect (a reductionist term in itself) her manic-depressive psychosis in the form of ambiguity and polysemousness. This is hardly a profound diagnosis.

\section{Robert E. Seaman \\ Los Angeles Pierce College}

\section{Reply:}

As the "dangerous" and "misguided" critic who wishes to "debunk" psychoanalysis, I feel somehow responsible for the challenges neuroscience has presented to Freud's theory of the psyche. But biological emendations have been taking place for good reason. We must remember that, for much of this century, not only the psychoses, such as schizophrenia, autism, and Tourette syndrome, but even disorders like tuberculosis, tertiary syphilis, parkinsonism, neurodermatitis, ulcerative colitis, essential hypertension, epilepsy, and premenstrual syndrome were thought by some to be psychological in origin and there- 